\title{
Chronic thromboembolic pulmonary hypertension and pulmonary endarterectomy: a rapid guide to diagnosis and management
}

\author{
Andrea Maria D’Armini
}

Division of Cardiac Surgery, Foundation "I.R.C.C.S. Policlinico San Matteo", University of Pavia, School of Medicine, Pavia, Italy

\author{
Address for correspondence: \\ Andrea Maria D'Armini \\ Division of Cardiac Surgery \\ Foundation "I.R.C.C.S. Policlinico San Matteo", \\ University of Pavia, School of Medicine \\ 27100 Pavia, Italy \\ E-mail: darmini@smatteo.pv.it; \\ andreamaria.darmini@unipv.it
}

\section{Summary}

Chronic thromboembolic pulmonary hypertension (CTEPH) represents the only type of pulmonary hypertension surgically treatable and curable, in the majority of cases, avoiding the need of lung transplant. This life-saving conservative surgery is called pulmonary endarterectomy (PEA).

To date, CTEPH is still under-diagnosed, and nowadays only few physicians are aware of the benefits of PEA. Clinical suspicion is the first step for diagnosis of CTEPH. Echocardiography, lung perfusion and ventilation scan, and right heart catheterization are useful for the diagnosis. Pulmonary angiogram, CT scan, and a multidisciplinary assessment are preliminary to surgical indication for PEA. PEA may have hemodynamically dramatic and immediate effects with a prompt restoration of normal values in most cases. Riociguat, a stimulator of soluble guanylate cyclase, is the only specific drug for nonoperable CTEPH patients or those with persistent/ recurrent disease after surgery.

KEY WORDS: chronic tromboembolic pulmonary hypertension, CTEPH, pulmonary endarterectomy, PEA, riociguat.

Introduction

Chronic thromboembolic pulmonary hypertension (CTEPH) is the only form of pulmonary arterial hypertension (PAH) potentially curable (1). It is due to the incomplete destruction of the thromboembolic material leftover from previous episodes of acute pulmonary embolism (PE). The elective care is the removal of the obstruction by pulmonary endarterectomy (PEA), a surgical operation performed only in few centers in the world (Figure 1). The CTEPH is a complex disease due to the difficult diagnosis often late performed, the therapeutic indication to surgery possible only in experienced Centers, the drug therapy and the follow-up to be administered by devoted specialized physicians: therefore a multidisciplinary approach to the patient is essential to ensure excellent results (2). The prevalence of CTEPH in patients surviving an acute pulmonary embolism (ca. $80 \%$ ) is calculated between $0.5-3.8 \%$, as to say an incidence of 2,000 new cases/year in Italy (3). Nevertheless, the honeymoon asymptomatic period may last months, and even years.

The main feature of CTEPH is the lack of a pathognomonic clinical manifestation and the frequent absence of a venous thromboembolism history, so it is frequently under-diagnosed. When there is a suspicion of CTEPH, three objectives should to be achieved:

- to confirm the presence of pulmonary hypertension; to identify the etiology;

to determine the appropriate treatment.

\section{The diagnostic work-up}

\section{First level exams}

The first level exams are the electrocardiogram (EKG), chest $\mathrm{X}$-ray and echocardiography. EKG and chest $X-$ ray tests are designed to highlight nonspecific signs of pulmonary hypertension
The right heart catheterization is the only test to confirm the presence of PAH.
$(\mathrm{PH})$, while echocardiography estimates the pressure in the pulmonary artery or the presence of intra-cardiac defects responsible for $\mathrm{PH}(4-8)$.

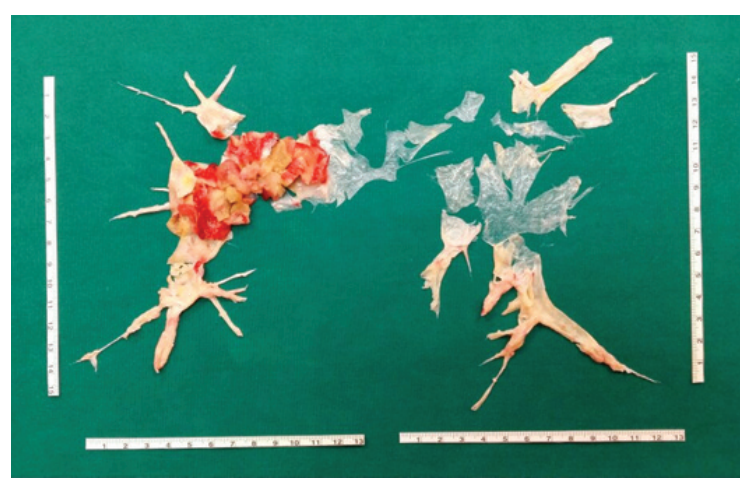

Figure 1 - Pulmonary endarterectomy casts from a patient with complex and severe case of CTEPH (Pavia, 2014). 


\section{Second level exams}

Tests of the second level are the right heart catheterization and pulmonary ventilation-perfusion scan $(9,10)$.

The integrated analysis of vascular and parenchymal phases allow the radiologist to exclude thoracic rare diseases causing $\mathrm{PH}$ other than CTEPH.

The right heart catheterization is the only test that can confirm the presence of $\mathrm{PH}$. The pulmonary ventilationperfusion scan is important to differentiate the CTEPH from the idiopathic $\mathrm{PAH}$ by the presence of a mismatch between ventilation and perfusion lung $(11,12)$.

\section{Third-level exams}

They are the pulmonary arteriography and the CT scan to identify the site and extension of the pulmonary arterial lesions. Pulmonary angiography is still considered the gold standard in the diagnosis of CTEPH to assess the accessibility of the surgical injury (13-16). The most common signs of CTEPH are the intimal irregularities, defects as pocket or intravascular networks, sudden reduction of the vascular dimension or amputation of the vase, frequently combined with bronchial artery dilation (Figure 2). In our center, this method has been replaced by chest CT thanks to the possibility of using devices 64 detectors and to the growing expertise of radiologists in using this method. Vascular phase confirms the thromboembolic etiology and allows to specify the localization and extension of embolic lesions, to identify the size and the thickness of the vessel wall and to identify the presence of atherosclerotic calcifications in the wall. The integrated analysis of vascular and parenchymal phases allows radiologist to exclude thoracic rare diseases causing $\mathrm{PH}$ with obstructive symptoms similar to CTEPH as the pulmonary artery sarcoma, the fibrosing mediastinitis and mediastinal neoplasms.

\section{Drug therapy}

Medical therapy is not able to heal the CTEPH. The most important drugs are anticoagulants to prevent re-

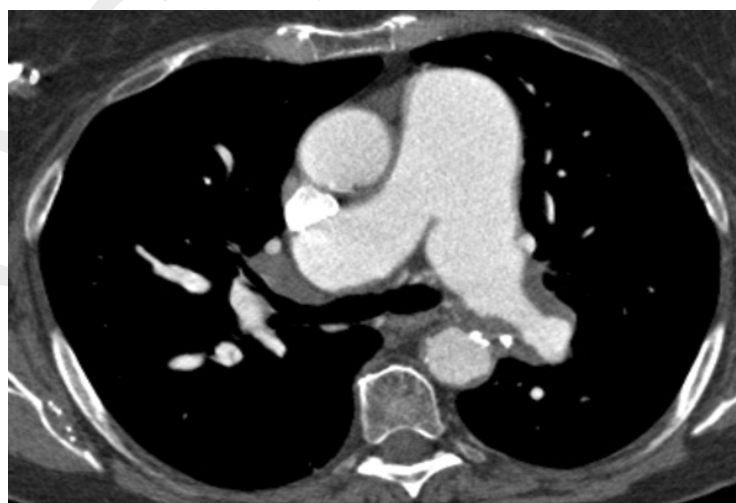

Figure 2 - CT scan in a case of CTEPH with proximal defect: combined intimal irregularities of the pulmonary artery main branch and bronchial artery dilatation. current VTE and pulmonary circulation selective vasodilators. The curable treatment is the PEA. If some patients are inoperable or have persistent or recurrent CTEPH after surgery, a specific drug therapy could be used: Riociguat (17), a stimulator of soluble guanylate cyclase (sGC). To date,
Riociguat is the only drug for PAH having for CTEPH a specific indication

Riociguat is the only drug designed for $\mathrm{PAH}$ having a specific indication for CTEPH not operable or persistent/recurrent after surgery thanks to the results of ad hoc RCT. Other specific drugs for PAH failed to reach the primary end-point in placebo-controlled trial (18). Only a small percentage of patients with CTEPH is not candidates to PEA (19) for the presence of lesions located exclusively at a very distal level or associated with other parenchymal lung diseases (e.g. severe pulmonary emphysema). In these cases the surgical alternative if indicated, is represented by bilateral lung transplantation.

\section{Surgical treatment (PEA)}

\section{The indications for PEA (pulmonary endarterectomy)} are:

- clinical: patient with functional class WHO II, III, IV. The clinical spectrum in which the EAP is indicated is therefore broad, ranging from moderately symptomatic forms in young patients at high risk cases in elderly patients with early multiple organ dysfunction;

- hemodynamic: the presence of PVR> 300 dyne * $\mathrm{s}$ * $\mathrm{cm}-5$ or a value of mean pulmonary artery pressure at rest $>25 \mathrm{mmHg}$ at the right heart catheterization;

- anatomical: the location and extent of the disease within the pulmonary arterial circulation are the main determinants operability, although the accessibility of the lesions is strongly influenced by the experience of the surgeon.

The interdisciplinary collaboration is important for operability judgement: advanced age, associated comorbidities, severe right ventricular failure and a long duration of the disease should not be considered as absolute exclusion criteria. A careful evaluation of the indication for PEA is a key factor in the management of patients with CTEPH. Otherwise, the non-appropriated assignment of some patient to surgery may be fatal. It is therefore essential referring the patient to an experienced center both for PEA and lung transplantation $(20,21)$.

The operative mortality of PEA intervention has undergone a significant decrease from $22 \%$ of the first pub-
The hemodynamic changes after PEA may be dramatic immediately into the operating room. lished series in the second half of the 80 s to the current $2-5 \%$ after overcoming the learning curve plateau (22). It is therefore considered obsolete the belief that PEA may be associated 
with high morbidity and mortality, such as having to reserve intervention for the sickest patients. The functional improvement strictly depends on the hemodynamic changes after PEA.

The hemodynamic changes after PEA may be dramatic immediately into the operating room, with a regular return to normal values in most cases $(23,24)$. Within the first few days post-surgery there was also an initial recovery of cardiac function, with a clear reduction of right ventricular dilatation. One year after it documents the reverse remodeling of the right ventricle, with the disappearance of ventricular hypertrophy and the recovery of a normal kinesis (24). The functional improvement of patients instead occurs more gradually and is linked to the age of the patient or to the duration of the disease.

Currently $90 \%$ of patients referred to a referral Centre for CTEPH is judged operable, thanks to an optimal

Currently $90 \%$ of patients referred to a CTEPH Centre is judged operable. selection of patients referred by the peripheral centers, and to the experience that has allowed to operate patients with distal disease, removing patients from the waiting list for lung transplantation (25). The age of patients has increased over the years. Age, however, does not affect the outcome of surgery in standardization hemodynamics and survival in the medium and long term.

\section{References}

1. D'Armini AM, Cattadori B, Monterosso C, Klersy C, Emmi V, Piovella F, Minzioni G, Viganò M. Pulmonary thromboendarterectomy in patients with chronic thromboembolic pulmonary hypertension: hemodynamic characteristics and changes. Eur J Cardiothorac Surg. 2000 Dec;18(6):696-701; discussion 7012.

2. Barzaghi N, Maurelli M, Emmi V, Minzioni G, D’Armini AM, Montecucco C, Salvaneschi L, Barone M, Piovella F. Pulmonary thromboendarterectomy in a patient with cryoagglutinins. J Cardiothorac Vasc Anesth. 2000;14(4):447-8.

3. D'Armini AM, Cattadori B, Monterosso C, Emmi V, Piovella F, Vigano M. Surgical therapy for chronic thromboembolic pulmonary hypertension: criteria for choosing lung transplant vs thromboendarterectomy. J Heart Lung Transplant. 2001;20(2):218

4. Ghio S, Raineri C, Scelsi L, Recusani F, D'armini AM, Piovella F, Klersy C, Campana C, Viganò M, Tavazzi L. Usefulness and limits of transthoracic echocardiography in the evaluation of patients with primary and chronic thromboembolic pulmonary hypertension. J Am Soc Echocardiogr. 2002;15(11):1374-80.

5. Enea I, Ghio S, Bongarzoni A, Casazza F, D'Armini AM, Favretto G, Roncon L, Rubboli A, Serafini O, Zonzin P, D'Agostino C. Echocardiographic alterations suggestive of pulmonary hypertension in the Italian ultrasonography laboratories. Epidemiological data from the INCIPIT study (INCidence of Pul- monary Hypertension in Italian ulTrasonography laboratories). G Ital Cardiol (Rome). 2010;11(5):402-7.

6. Ghio S, Klersy C, Magrini G, D’Armini AM, Scelsi L, Raineri C, Pasotti M, Serio A, Campana C, Viganò M. Prognostic relevance of the echocardiographic assessment of right ventricular function in patients with idiopathic pulmonary arterial hypertension. Int J Cardiol. 2010;140(3):272-8.

7. Fedullo $\mathrm{P}$, Kerr KM, Kim NH, Auger WR. Chronic thromboembolic pulmonary hypertension. Am J Respir Crit Care Med. 2011;183(12):1605-13.

8. Piazza G, Goldhaber SZ. Chronic thromboembolic pulmonary hypertension. N Engl J Med. 2011;364: 351-60.

9. Arbustini E, Morbini P, D'Armini AM, Repetto A, Minzioni G, Piovella F, Viganó M, Tavazzi L. Plaque composition in plexogenic and thromboembolic pulmonary hypertension: the critical role of thrombotic material in pultaceous core formation. Heart. 2002;88(2):177-82.

10. Zoia MC, D’Armini AM, Beccaria M, Corsico A, Fulgoni P, Klersy C, Piovella F, Viganò M, Cerveri I; Pavia Thromboendarterectomy Group. Mid term effects of pulmonary thromboendarterectomy on clinical and cardiopulmonary function status. Thorax. 2002;57(7):608-12.

11. Recusani F, Di Matteo A, Gambarin F, D’Armini A, Klersy C, Campana C. Clinical and therapeutical follow-up of HIV-associated pulmonary hypertension: prospective study of 10 patients. AIDS. 2003;17 Suppl 1:S88-95.

12. Cerveri I, D'Armini AM, Viganò M. Pulmonary thromboendarterectomy almost 50 years after the first surgical attempts. Heart. 2003;89(4):369-70.

13. D'Armini AM, Zanotti G, Viganò M. Pulmonary endarterectomy: the treatment of choice for chronic thromboembolic pulmonary hypertension. Ital Heart J. 2005;6(10):861-8.

14. Piovella F, D'Armini AM, Barone M, Tapson VF. Chronic thromboembolic pulmonary hypertension. Semin Thromb Hemost. 2006;32(8):848-55

15. D'Armini AM, Zanotti G, Pozzi M, Nicolardi S, Tramontin C, Ruggieri VG, Morsolini M, Tancredi F, Monterosso C, Viganò M. Surgical treatment of chronic thromboembolic pulmonary hypertension with pulmonary endarterectomy. G Ital Cardiol (Rome). 2006 Jul;7(7):454-63.

16. Petrucci L, Carlisi E, Ricotti S, Klersy C, D’Armini AM, Viganò M, Dalla Toffola E. Pulmonary endarterectomy in chronic thromboembolic pulmonary hypertension: short-term functional assessment in a longitudinal study. Eura Medicophys. 2007;43(2):147-53.

17. Ghofrani HA, D'Armini AM, Grimminger F, Hoeper MM, Jansa P, Kim NH, Mayer E, Simonneau G, Wilkins MR, Fritsch A, Neuser D, Weimann G, Wang C, for the CHEST-1 Study Group. Riociguat for the Treatment of Chronic Thromboembolic Pulmonary Hypertension. N Engl J Med. 2013;369:31929.

18. Jaïs $X$, D’Armini AM, Jansa $P$, Torbicki $A$, Delcroix $M$, Ghofrani HA, Hoeper MM, Lang IM, Mayer E, PepkeZaba J, Perchenet L, Morganti A, Simonneau G, Ru- 
bin LJ for the BENEFiT Study Group. Bosentan for treatment of inoperable chronic thromboembolic pulmonary hypertension: BENEFiT (Bosentan Effects in iNopErable Forms of chronic Thromboembolic pulmonary hypertension), a randomized, placebo-controlled trial. J Am Coll Cardiol. 2008 Dec 16;52(25): 2127-34.

19. Mayer E, Jenkins D, Lindner J, D’Armini A, Kloek J, Meyns B, Ilkjaer LB, Klepetko W, Delcroix M, Lang I, Pepke-Zaba J, Simonneau G, Dartevelle P. Surgical management and outcome of patients with chronic thromboembolic pulmonary hypertension: results from an international prospective registry. J Thorac Cardiovasc Surg. 2011;141(3):702-10.

20. Corsico AG, D'Armini AM, Cerveri I, Klersy C, Ansaldo E, Niniano R, Gatto E, Monterosso C, Morsolini M, Nicolardi S, Tramontin C, Pozzi E, Viganò M. Long-term outcome after pulmonary endarterectomy. Am J Respir Crit Care Med. 2008 Aug 15;178 (4):419-24.

21. Pepke-Zaba J, Delcroix M, Lang I, Mayer E, Jansa P, Ambroz D, Treacy C, D’Armini AM, Morsolini M, Snijder R, Bresser P, Torbicki A, Kristensen B, Lewczuk J, Simkova I, Barberà JA, de Perrot M, Hoeper
MM, Gaine S, Speich R, Gomez-Sanchez MA, Kovacs $G$, Hamid AM, Jaïs X, Simonneau G. Chronic thromboembolic pulmonary hypertension (CTEPH): results from an international prospective registry. Circulation. 2011;124(18):1973-81.

22. Jenkins DP, Madani M, Mayer E, Kerr K, Kim N, Klepetko W, Morsolini M, Dartevelle P. Surgical treatment of chronic thromboembolic pulmonary hypertension. Eur Respir J. 2013;41(3):735-42.

23. D'Armini AM, Zanotti G, Ghio S, Magrini G, Pozzi M, Scelsi L, Meloni G, Klersy C, Viganò M. Reverse right ventricular remodeling after pulmonary endarterectomy. J Thorac Cardiovasc Surg. 2007;133(1):162-8.

24. Ghio S, Morsolini M, Corsico A, Klersy C, Mattiucci G, Raineri C, Scelsi L, Vistarini N, Oltrona Visconti L, D'Armini AM. Pulmonary arterial compliance and exercise capacity after pulmonary endarterectomy. Eur Respir J. 2014;43(5):1403-9.

25. D'Armini AM, Morsolini M, Mattiucci G, Grazioli V, Pin M, Valentini A, Silvaggio G, Klersy C, Dore R. Pulmonary endarterectomy for distal chronic thromboembolic pulmonary hypertension. J Thorac Cardiovasc Surg. 2014 Sep;148(3):1005-12. 